\title{
Psicologia socioambiental: uma psicologia social articulando psicologia, educação e ambiente
}

\section{Environmental psychology: a social psychology Articulating psychology, education and environment}

Recibido: 15/07/2013

Revisado: 03/09/2013

Aceptado: 05/11/2013

\begin{abstract}
The paper presents a reflexion about the social-environmental psychology as a social psychology that aims to articulate psychology, education and environment. It is proposed a type of social-environmental intervention thought as an original and innovative strategy, whose pedagogical influences would transcend the social-environmental field to which is directed, reverberating its effects to beyond its boundaries. We search, with this reflexion, to recover the thought (near the Frankfurt School) of Kurt Lewin, transposing its postulations to the contemporary world. Thus, the proposed social-environmental intervention would
\end{abstract}

\author{
Eda Terezinha de Oliveira Tassara, \\ Universidade de São Paulo, Brasil
}

Héctor Omar Ardans-Bonifacino y

Universidade Federal de Santa Maria, Brasil

\section{Nicole Nöthen de Oliveira}

Universidade de São Paulo, Brasil

\section{Nota de autores:}

Eda Terezinha de Oliveira Tassara. Professora Titular do Instituto de Psicologia da Universidade de São Paulo; Coordenadora do grupo de Política Ambiental do Instituto de Estudos Avançados da Universidade de São Paulo; Presidente do Instituto Brasileiro de Educação, Ciência e Cultura - IBECC/UNESCO-Comissão de Sáo Paulo; e Coordenadora do Laboratório de Psicologia Socioambiental e Intervenção (LAPSI-USP), Presidente do Conselho Deliberativo do Fundo Brasileiro de Educação Ambiental (FUNBEA).

Héctor Omar Ardans-Bonifacino. Professor Adjunto do Departamento de Psicologia da Universidade Federal de Santa Maria (UFSM-RS). Livre-Docente em Psicologia Socioambiental. Pesquisador do grupo de Política Ambiental do Instituto de Estudos Avançados da Universidade de Sáo Paulo.

Nicole Nöthen de Oliveira. Psicóloga. Mestranda do Programa de Pós-Graduaçăo em Psicologia Social da Universidade de Sáo Paulo - bolsista CAPES, sob orientação da Professora Eda Tassara; Pesquisadora integrante do Laboratório de Psicologia Socioambiental e Intervenção (LAPSI-USP). 
consist in a draft of a cultural reconstruction method of the present in the direction of a utopian future, committed with the democracy and emancipation, a way to a true pacific revolution.

Key words: social psychology, social-environmental psycholohy, social-environmental intervention, education, environment

"O psicólogo encontra-se inserido em uma terra rica e vasta, cheia de acontecimentos estranhos: há homens se matando, uma criança brincando, uma criança movimentando seus lábios tentando dizer sua primeira palavra, uma pessoa que, tendo se apaixonado e se encontrado em uma situação infeliz, não está disposta ou não se sente capaz de encontrar uma saída, há um estado místico chamado hipnose,o qual a vontade de uma pessoa parece governar outra,há uma busca das maiores e mais difíceis metas; lealdade a um grupo; sonhar, planejar, explorando a palavra, e assim por diante, sem fim. É um imenso continente cheio de fascínio e poder com muitos trechos de terra onde ninguém jamais pôs os pés. Psicologia é para a conquista deste continente, para descobrir onde seus tesouros estão escondidos para investigar seus pontos de perigo, para dominar suas imensas forças, e utilizar as suas energias. Como se poderia alcançar essa meta?" (Lewin K., 1940, Marrow, A., 1969, p. 3)

O presente ensaio busca evidenciar as contribuiçōes necessárias, embora não suficientes, advindas da Psicologia Social para que o campo teórico que denominamos de Psicologia Socioambiental possa abranger com competência analítica o objeto de estudo intervenção socioambiental. Neste cenário, emergem, entre outras, práticas que se enquadram em buscas de interferência sobre o desempenho de processos sociais, configurando novas abordagens e métodos que se constroem intencionando-se influenciar o futuro socioambiental (Ardans, no prelo). Conjecturamos que seriam projeçóes derivadas da expansão de efeitos, sobre o sistema científico mundial, da aliança instrumental processada entre cientistas, industriais, políticos, militares e sistemas de informação que culminaram na produção da chamada big science nos EUA, agora genericamente denominada de sistema científico-tecnológico. intervenção socioambiental proposta consistiria em esboço de um método de reconstruçấo cultural do presente na direçấo de um futuro utópico, em compromisso com a democracia e a emancipação, um caminho para uma verdadeira revolução pacífica.

Palavras-chave: psicologia social, psicologia socioambiental, intervenção socioambiental, educação, ambiente

Sob tal modelo de funcionamento da instituição científica, não ocorrem separações temporais entre a produção do conhecimento científico e sua aplicação tecnológica. Tais resultados propagaram-se para a sociedade mundializada de maneira a dificultar a separaçáo entre etapas de conhecimento da realidade social e etapas de desenvolvimento e aplicação de tecnologias sociais voltadas para a sua transformação, em funçâo da acelerada dinâmica que a vem caracterizando e desses modelos epistemológicos hegemônicos. Repercutindo essa impossibilidade, observa-se a emergência de uma pragmática investigativa e interventiva, que interrelaciona, em seus procedimentos, conhecimentos advindos das teorias de e em planejamento, com conhecimentos (processos e produtos) advindos das ciências sociais e humanas, bem como das teorias de informação. Conforme já referido, esta classe de procedimentos consiste na classe das intervençóes socioambientais.

Neste sentido, acredita-se que a intervenção socioambiental, entendida aqui como uma estratégia de ação social, articularia, em seu desenvolvimento e implementação, questôes atinentes à psicologia, à educaçấo e ao ambiente. A esse respeito, define-se, com base em trabalho anterior (Tassara, 1982), a prática de intervenção educacional como uma prática inovadora de socialização (ou re-socialização), podendo esta definição ser considerada como tendo um significado próximo ao que se está atribuindo aqui à expressão intervenção socioambiental. Assim, "a prática da intervenção educacional por ação estratégica constitui-se em uma estratégia de ação social que, exercendo funçôes pedagógicas, aumentaria o alcance histórico e o significado social de suas repercussóes imediatas, e, por meio da crítica política de seu desempenho, conduziria a um maior entendimento da estrutura social". (p. 7)

Considerando o que foi exposto acima, parte-se dos seguintes pressupostos: 
1. A Psicologia Socioambiental é uma Psicologia Social definida como um campo marginal e híbrido de conhecimento situado na confluência da Sociologia, da Psicologia, da Antropologia e da Psicanálise (Fernandes, 1969).

2. O paradigma eleito para nortear estas investigações éo paradigma da Teoria Crítica, que considera indissociáveis a ação política e o exercício da pesquisa social (Guba, 1990);

3. As metas políticas dos estudos e investigações são norteadas pela busca de recuperação das vinculações necessárias entre identidade, política e ética (Tassara \& Ardans, 2012).

4. A metodologia da pesquisa social em pauta envolve a articulação entre métodos convencionais e a pesquisaação (Lewin, 1948).

5. A tríade cultura técnica ambiente forma uma imbricação de relaçóes indissociáveis de causa e efeito que são parte inerente da criação inovativa (Bardi, 1983).

6. A Política Ambiental consiste na construção intencional, poética e compartilhada do futuro (Bardi, 1983).

Assim, a intervenção socioambiental, tal como apresentada, permitiria a construção de um caminho utópico na direção de um aprimoramento das formas de convívio social pari passu com a transformação psicossocial dos sujeitos nela envolvidos, via intervençóes educativas e democráticas. Nesse sentido, esta proposta de intervenção socioambiental pode ser considerada como uma estratégia original e inovativa de educação transformadora, cujas influências pedagógicas transcenderiam o campo socioambiental em questão, reverberando e ampliando seus efeitos para além de suas fronteiras.

\section{Contribuições da Psicologia Social}

Considerando os resultados de estudos recentes realizados sob a perspectiva da Clínica Psicossocial da Identidade (Ardans, 2009), entende-se que o processo psicológico, substrato da relação indivíduo-ambiente, se manifesta de forma a não permitir uma separação entre estes elementos

\footnotetext{
"A história da psicologia já demonstrou de maneira irrecusável, pelo menos desde a obra pioneira de Franz Brentano, no século XIX, que não há percepção, mas percepção de... não há consciência, mas consciência de... não há memória, mas memória de... Ou seja, a relação sujeitos/ambiente é indissociável. Mas, tais objetos (ambientes), em relação aos sujeitos (via percepçáo, consciência, memória, imaginaçáo, pensamento, linguagem), não surgem do vazio, eles existem e consistem em uma produção social (que é, ao mesmo tempo, cultural
}

e política), na mesma proporção em que ambiente é a organização humana no espaço total, de tal forma que ambiente é sempre, como afirma Milton Santos, socioambiente." (p. 14)

Já no que diz respeito aos teóricos clássicos da Psicologia Social, consideram-se as contribuiçôes de Solomon Asch (1952). De acordo com Asch, o indivíduo estaria inscrito em um campo de forças que determinariam as principais características advindas de sua interação com o ambiente. A respeito das relaçōes sociais, Asch (1952), afirma que

\footnotetext{
"Não se começa com um "você" ou um "eu". Estes se desenvolvem em relação recíproca, como partes de um campo recíproco; não pode haver um "eu" sem um "você", nem "eles" sem "nós". Naturalmente, as categorias, a que se referem estas simples designaçóes, ocorrem em contextos muito concretos. O "você" é, em geral um dos pais, um empregador, ou um amigo. Mas estas categorias concretas também são produtos de processos sociais específicos; não se começa como amigo ou um primo. Na verdade, as categorias de marido e mulher, ou pai, mãe e filho, são fatos psicossociais, no sentido mais fundamental; sua significação não é, de maneira alguma, comunicada inteiramente, nem inteiramente determinada pelas diferenças biológicas e pelas relaçōes entre os homens, mulheres e crianças. No sentido estrito, é através de interaçóes concretas que os seres humanos se tornam pais, mães, maridos e esposas. (p. 217)" (também Goffman, 1959).
}

Outro autor que muito contribuiu para uma inclusão consistente da dimensão psicossocial nas teorias do sujeito, enfatizando-a, foi George Herbert Mead, especialmente em sua obra "Mind, Self and Society" (Mead, 1934; também Ardans, 2013).

George Mead, teórico do pragmatismo, assim como John Dewey (1939) (também Pogrebinschi, 2005), Charles Peirce (1972) e William James (1985), fez uma revisão dos primeiros quatro volumes da Völkerpsychologie ${ }^{1} \mathrm{de}$ Wundt (veja também Araujo, 2010), realizando uma crítica às postulaçôes deste autor. A síntese elaborada por Mead em resposta à antítese estabelecida por Wundt - entre a biologia, de um lado, e a sociedade e a cultura, de outro - consistiu na inserção do conceito de Self como mediador das interações

1 De acordo com Robert Farr (1996), "os objetos de estudo da Völkerpsychologie de Wundt eram a linguagem, a religião, os costumes, o mito, a magia e fenômenos semelhantes. Esses fenômenos coletivos emergem da 'recíproca interação de muitos' (Wundt, 1996, p. 3) e, segundo Wundt, eles não podem ser explicados em termos de consciência do indivíduo, que era a base de seu laboratório científico. A psicologia social de Wundt era, pois uma forma de Geisteswissenschaft. A psicologia continuava a ser a ciência da mente em suas manifestaçóes externas, isto é, em termos de cultura. Ela continuava a ser uma ciência, mas um tipo diferente de ciência: uma ciência humana e social" (Farr, 1996, p. 42). 
entre a mente do indivíduo e a sociedade em que este se encontra (Farr, 1996). De acordo com Mead (1934),

\begin{abstract}
"O self tem um caráter que é diferente daquele do organismo fisiológico, propriamente. O self é algo que tem um desenvolvimento; não está lá inicialmente, no nascimento, mas surge no processo da experiência e atividade social, isto é, se desenvolve em determinado indivíduo como um resultado de suas experiências naquele processo como um todo e com outros indivíduos dentro deste processo". (p. 135).
\end{abstract}

A linguagem também se tornou um ponto central na teoria de Mead. Este autor tratava a linguagem como um fenômeno inerente ao social, diferentemente de seus colegas comportamentalistas, como Watson (na psicologia) e F. H. Allport (na psicologia social). Por esse motivo, Herbert Blumer (1969), nomeou o empreendimento intelectual de Mead de interacionismo simbólico (Farr, 1996).

Neste sentido, o filósofo John Dewey (1939) contribuiu de forma significativa para a discussão a respeito da interação humana com teor democrático, necessária, a nosso ver, para o empreendimento de açóes estratégicas visando o bem comum. Este autor desenvolveu uma teoria do exercício da democracia como um modo de vida, de forma que os sujeitos sejam livres para desenvolver uma inteligência criativa, entendida esta como o meio para "projetar fins novos e cada vez mais complexos, (...) a fim de buscar possibilidades que não são previamente estabelecidas" (De Franco \& Pogrebinschi, 2008, p. 152) ${ }^{2}$.

A Psicologia Socioambiental sustentaria e fundamentaria, entáo, processos de intervençóes socioambientais, no intuito de potencializar as interaçóes pessoa-ambiente, incrementando seu teor democrático e contribuindo para a redução da disrupção ambiental. Para tal, torna-se necessário envolver a participação. Dessa forma, a intervenção socioambiental assim pensada, pode ser definida, primordialmente, como os resultados da implementação de projetos estruturados mediante um planejamento estratégico (Costa, 1986; Gentilini, 1999; Melo, 1987, 1979, 1977; Tassara, 1986) e participativo, direcionado à solução de um problema ou problemática inscrito/a em uma unidade territorial - esta última denominada de campo socioambiental.

2 De Franco e Pogrebinschi são os autores brasileiros que mais tem contribuído para introduzir no Brasil as idéias pragmatistas na Ciência Política. Sugere-se ampliar as leituras a partir de Pogrebinschi (2005, 2009. 2011) e de Feres Junior e Pogrebinschi, 2010).
Partindo desta perspectiva, o diagnóstico relativo ao campo socioambiental em questão, para garantir seus compromissos democráticos, realizar-se-ia por meio de laboratórios sociais, onde se utilizaria a metodologia da pesquisa-ação, postulada por Kurt Lewin - ou, ao menos, inspirar-se-ia nela. Lewin entendia que a constituição do indivíduo e suas atitudes seriam constantemente influenciadas por forças advindas do ambiente e da interaçáo com outras pessoas.

Além disso, entende-se que, para se responder aos compromissos postulados, toda ação deve ser pautada por uma ética comunicativa, tal como proposta por Jürgen Habermas (1981, 1983), no desenvolvimento de sua teoria da açáo comunicativa (TAC). De acordo com Ardans (2009),

\footnotetext{
"Ao mesmo tempo, retomando as propostas de Kurt Lewin a respeito de formação de grupos democráticos, trata-se de propiciar e levar adiante um trabalho em grupos entendido, com Habermas, enquanto espaços de locução nos quais possa se desenvolver capacidade argumentativa dos participantes como forma exclusiva de sustentaçáo da crítica. Desta maneira, uma reivindicação legítima do ponto de vista ético, de um setor da população, transforma-se em crítica a partir da argumentação elaborada em grupo. Este empreendimento, denominado por Eda Tassara como laboratório social recolhe a iniciativa de Lewin, atualizando-a em termos teóricos e metodológicos sem perder de vista o horizonte político que já caracterizava a proposta daquele pesquisador". (p. 165)
}

Lewin escreveu obras dedicadas à descrição da natureza dos campos de força que circundariam os indivíduos e influenciariam diretamente seus sentimentos, pensamentos e açôes, notadamente nas obras "Teoria de campo em ciência social" (1951) e "Princípios de psicologia topológica" (1973). Outras obras de Lewin avaliaram e afirmaram a importância da composição de um grupo na dinâmica de seu funcionamento. $\mathrm{O}$ autor concluiu que o tipo de liderança de um grupo (democrática ou autoritária) afeta fundamentalmente as atitudes e posturas tomadas pelos seus membros - ou seja, sua dinâmica. É o caso discutido na obra "Problemas de dinâmica de grupo" (Lewin 1948).

\section{Desenvolvimento e implementação de intervenções socioambientais}

Dessa forma, os seguintes elementos-base seriam necessários para se estruturar o processo de planejamento de um projeto de intervenção socioambiental, tal como o proposto:

1. Um campo socioambiental configurado por um(a) determinado(a) problema/problemática, ou seja, uma situação que requer solução (Lalande, 1926). 
2. Um grupo de atores sociais dispostos a se engajar no planejamento participativo da açẫo destinada a enfrentar a referida problemática.

3. O grupo acima indicado seria composto por sujeitos técnicos ou grupo facilitador da participação e da intervenção e sujeitos envolvidos na problemática.

Primeiramente, em busca de clareza no diagnóstico da problemática e, consequentemente, na decisáo do caminho a ser seguido pelo planejamento da intervenção, propõe-se que o grupo, que também pode ser denominado de coletivo, empreenda uma sequência de três questionamentos, todos de igual importância:

(a) Qual éo(a) problema/problemática?, (b) Por que o(a) problema/problemática identificado(a) constitui-se em problema/problemática?; e (c) Para quem o(a) problema/ problemática identificado apresenta-se como problema/ problemática?3

É importante ressaltar que a delimitação do(a) problema/ problemática sempre dependerá da perspectiva e do padrão de referência - ou seja, a situação desejável, que deve ser determinada pelo coletivo, através das discussóes e argumentaçóes pautadas pela metodologia já mencionada.

3 No que diz respeito ao que faz parte da determinação da situação ambiental objeto do diagnóstico a ser feito pelo coletivo, estes determinantes são estabelecidos através de três tipos de critérios: Critérios éticos - "certo ou errado"; Critérios políticos - "bom ou ruim"; e Critérios estéticos - "bonito ou feio". De acordo com Van Den Besselaar (1994), na obra "As palavras têm a sua história", podemos encontrar o que segue, a respeito das palavras "ética", "política” e "estética”. Ética - \$295.B.2. A evolução semântica de "domicílio, morada" (= "o local onde uma pessoa costuma se achar» para "costume» ocorre também no subst. gr. éthos = «morada [de animais ou de homens]»); mais tarde, ficou com o sentido de "costume» e, finalmente, com o de «bom costume». (p. 438); Política- \$161.B. O adj. gr. politikós queria dizer, além de «civil», também «social» e "político», dois qualificativos que, na democracia grega, estavam estreitamente ligados um ao outro, sobretudo, em Atenas, todo e qualquer cidadão masculino, livre e maior, podia ser chamado a exercer um cargo político. Aristóteles define o homem como zóon (...) politikón, definição que, em português, se poderia traduzir jocosamente com as palavras «bicho político", mas que, na realidade, quer dizer «animal social / que vive [naturalmente] numa sociedade»; \$161.B.1. O adj. port. "político» tinha, na época clássica, do mesmo modo que o adj. franc. policé, muitas vezes o sentido de "civilizado, bem educado» (...). (p. 331); Estética- \$197.D.2. O termo «estética» foi forjado pelo filósofo alemão A. G. Baumgarten (ca. 1750), precursor de Kant; a palavra deriva do subst. gr. áisthesis (= "percepção, sentimento»). (p. 356)
Neste sentido, é necessário que se busque, sempre, o conhecimento e explicitação das crenças e ideologias que fundamentam a perspectiva, e o padrão de referência, adotados, para que não se sustentem posicionamentos alienados e alienantes.

Embora esta seja uma tarefa difícil, uma vez que um grupo apresenta diversas perspectivas e opiniōes ("polifonia de visōes", -"multiplicidade de vozes e de consciências independentes”- Bahktin, 1981), este é o primeiro desafio de um coletivo, o qual deverá buscar a articulação de informaçôes, a gestão dos conflitos e, enfim, produzir consensos ou dissensos, através de reflexóes e do desenvolvimento de argumentaçóes que possam ir em direção ao maior esclarecimento possível da situação e às soluções possíveis.

Én este cenário que as propostas de Lewin e Habermas se encontram e podem articular açóes de atores de um determinado coletivo, onde todos, e cada um dos membros, deverão, em uma perspectiva utópica, encontrar ali um espaço de verdadeira locuçáo (Habermas, 1981, 1983), um espaço social promotor de livre expressão (Dallari, 2002; Prudente, 1996), onde se pode exercer a reflexividade crítica e a participação política direta e espontânea. É neste cenário ideal que as decisóes sobre ações, bem como suas avaliaçóes e reformulaçóes irão se dar, conforme o caso.

Em relação ao campo socioambiental, conforme referido, tomamos como referência a definição de socioambiente de Aziz Ab'Saber (2002) -veja também Santos (1982)- , qual seja, "a organização humana no espaço total, que compreende os fragmentos territoriais em sua totalidade" (s/p). Entende-se, assim, que a definição de um campo socioambiental dar-se-ia através da delimitação de uma unidade territorial que venha configurar uma forma específica de organização humana (Tassara \& Ardans, 2013).

O domínio territorial poderia, então, ser definido em função de homogeneidades de suas paisagens naturais, de sua organização humana, da morfologia das relaçóes sociais e suas interaçôes com os domínios da natureza, ou, ainda, arbitrariamente, através de delimitações políticoadministrativas, tais como municípios. A delimitação do campo socioambiental poderá ocorrer antes ou depois $\mathrm{da}$ definição da problemática, de acordo com as especificidades de cada situação. 
Os papéis desempenhados pelo indivíduo que "coordenará" as açóes deste grupo, de acordo com os compromissos elencados acima, seria o de propiciador de reflexão crítica, mediador de conflitos, facilitador de consensos e gestor de dissensos. Este indivíduo deve manejar a distribuição da fala dos membros do grupo, tentando evitar monopólios e atitudes coercitivas, bem como a produçáo de silêncios e silenciamentos.

Ainda de acordo com trabalhos anteriores (Tassara \& Ardans, 2006, 2013), existiriam duas categorias nas quais estes silêncios/silenciamentos poderiam vir a ser enquadrados: indicando desinteresse ou não motivação em relação às temáticas tratadas; ou por sustentar reflexão em curso (devido a uma personalidade introvertida).

Para esses autores, podem ser identificadas quatro fontes de origem destes silêncios/ "silenciamentos":

a) Por desconhecimento de informaçóes sobre a temática (ignorância). Neste caso, "diante do desconhecimento da existência de alternativas de pensamento em relação a um dado objeto, tudo se passa como se essas alternativas não existissem" (Tassara e Ardans, 2006). Caorsi (1994) chama este fenômeno de positividade lógica.

b) Por impedimento psíquico. Nesse caso, seria uma "constrição ao exercício da reflexividade pelo sofrimento gerado pela negação da ordem estabelecida, que coloca obstáculos para a emergência da consciência, dificultando-a ou impedindo-a" (Tassara \& Ardans, 2006). Segundo a psicanálise, essa interpretação seria denominada de negatividade psicológica.

c) Por arbitrariedade semântica. Considerando que o real é uma construção social e, portanto, sua representação lingüística é sempre contingente e arbitrária, o silêncio significaria entendimentos léxicos diferenciados. Dessa forma, dever-se-ia atentar para a manifestação de diferenciais semânticos buscando-se discursos alternativos que melhor venham corresponder aos significados compartilhados nas respectivas comunidades linguísticas.

d) Por alienação política. Neste caso, realidades são ativamente produzidas como náo existentes. Boaventura de Souza Santos (1995), a este respeito, afirma que "náo basta criar um novo conhecimento, é preciso que alguém se reconheça nele. De nada valerá inventar alternativas de realização pessoal e coletiva, se elas não são apropriáveis por aqueles a quem se destinam" (p. 333-334).
Assim, o facilitador da intervenção deverá estar atento para a manifestação destes processos, os quais podem afetar, e até impedir, o pleno desenvolvimento do planejamento, execução e avaliação das açôes da intervenção na direção da participação emancipatória dos membros do grupo. A participação emancipatória poderia ser definida, então também com base em estudos anteriores (Tassara \& Ardans 2013) - como a

\footnotetext{
"açáo de ser (fazer) parte de processos de transformação social que suponham nâo uma passividade dos atores (convocados de cima e de fora, meros receptores das conseqüências das políticas públicas), mas, pelo contrário, uma ação enquanto agentes do processo em todas as suas fases e para todos os efeitos" (p. 283).
}

Estes processos que ocorrem nestes espaços denominados de laboratórios sociais constituem o que se postula como palco para o desenvolvimento de uma clínica psicossocial da identidade. De acordo com Ardans (2009),

\begin{abstract}
"Sobre esta base, o procedimento laboratório social da clínica psicossocial da identidade torna possível o trabalho das pessoas nos grupos enquanto sujeitos, indissociavelmente, de linguagem e de açâo, sustentando processos de participação. Através destes processos, em que, ao mesmo tempo se constroem como sujeitos racionais questionam o tipo e grau de "participaçáo". Tal questionamento pode transformar um estado de inicial passividade (receptores dos efeitos de políticas públicas, p. ex.) em portador e protagonista de uma futura transformaçâo da legitimidade social pelo exercício de uma soberania lúcida e conscientemente procurada" (p. 165).
\end{abstract}

Os sujeitos envolvidos neste processo da Clínica Psicossocial da Identidade devem vir a ter a possibilidade de exercício de uma reflexão crítica e de um agir comunicativo (AC), conceito desenvolvido por Habermas (1983, 1981; vide também Bolzan, 2005). Buscar-se-ia, assim, formas de interação livre de dominação/coerção, privilegiando-se a argumentação (uso da racionalidade) como meio de se chegar a um entendimento. Esse conceito é descrito por Aragão (1997), da seguinte maneira:

\footnotetext{
"forma de mecanismo da coordenação das açóes baseadas na intersubjetividade do entendimento linguístico vai acarretar a total ausência de coerçẫo, já que as posiçóes assumidas deverâo levar em conta a possibilidade de que venham a ser contestadas pelos demais, devendo provar-se por suas pretensóes de validade, e não por qualquer influência externa ou pelo uso da força" (p. 54).
}

Supóe-se que as capacidades de refletir criticamente e de se comunicar apresentando clareza na argumentaçáo devem proporcionar, aos participantes e ao coletivo, a vivência de um espaço social promotor do que Habermas (1990) chamou de intersubjetividade ilesa, a qual sustentaria condiçōes para 
processos autonômicos (autonomia substituindo a heteronomia - esta associada à coerção). As interaçóes ocorridas nestes cenários seriam pautadas por compromissos com a democracia, onde a cooperação deveria substituir a coerção.

A ação comunicativa teria, dessa forma, grande potencial para a desconstrução de concepçóes provindas do mundoda-vida dos sujeitos participantes. Este mundo incluiria as tradições familiares e sociais, presentes nos espaços de socialização do sujeito, constituindo um estado - difícil de ser acessado com lucidez, não problematizado - ou seja, o "núcleo dogmático-intuitivo do pensamento", uma dimensão mítica e primitiva do pensamento de cada ser humano, sustentada em convicçóes forjadas pelo sujeito no curso de sua socialização, muito difíceis de serem transformadas racionalmente (Habermas, 1983).

Assim, o trabalho da ação comunicativa propiciaria o desenvolvimento de uma racionalidade crítica com o objetivo de se chegar a um consenso através da comunicação e argumentação (linguagem) e não da imposição (coerção), podendo ser questionadas, dessa forma, as tradiçóes e o que foi estabelecido através da socialização primária.

Pensando no empreendimento da ação comunicativa, a qual se utiliza da racionalidade comunicativa/argumentação como meio de produzir entendimentos, não se pode prescindir da importância do desenvolvimento da lógica (Piaget, 1970, 1945) e da moral (Kohlberg, 1981), para que esse tipo de interação/ação social se dê. Estas duas dimensóes do desenvolvimento psíquico envolvem capacidades de se empreender interaçóes que reflitam operaçóes caracterizadas pelos atributos da reversibilidade, reciprocidade e cooperação (Piaget, 1945), permitindo o empreendimento de açôes cooperativas - imprescindíveis para o planejamento participativo ou interativo - que são o meio e o objetivo dos laboratórios sociais. Cabe ressaltar que, dentro do campo teórico-conceitual formulado por Piaget, o conceito que se opóe a esse modo de interação (cooperação) se caracterizaria como uma relação baseada na coação ${ }^{4}$.

4 Piaget usa o termo coaçáo para descrever o tipo de relaçáo que Habermas chamou de coerção. Para fins desta reflexão, as definições dos dois termos náo guardam diferenças relevantes, e podem ser usadas para descrever a mesma situação, como podemos ver no trecho a seguir: "Existem, efetivamente, dois tipos extremos de relaçôes interindividuais: a coação que implica uma autoridade e uma submissão, conduzindo assim à heteronomia, e a cooperaçáo que implica a igualdade de direito ou autonomia, assim como a reciprocidade entre personalidades diferenciadas (Piaget, 1945, p. 168).
Dessa forma, a busca pelos esclarecimentos/ argumentos produtores dos consensos a respeito do planejamento da intervenção socioambiental pretendida, ofereceria ao analista dois processos: um processo hermenêutico, mediante a descrição das construções individuais efetuadas da maneira mais acurada possível e um processo dialético (Piaget, 1980), propiciando a comparação e o contraste entre as diferentes construçóes individuais. Estes processos estimulariam o pensamento crítico dos sujeitos envolvidos (do e no coletivo), assim como a avaliação do empreendimento da ação comunicativa. É na direção deste horizonte emancipatório que deve caminhar a intervenção - em busca da instauração de sujeitos conscientes e autônomos, capazes de reflexão crítica e atuação transformadora sobre sua própria situação e a situação daqueles ao seu redor.

Em geral, os atores envolvidos, em um processo de intervenção socioambiental tal como aqui proposto, são: o próprio Estado; os cidadãos; e os técnicos. É importante ressaltar que esta composição em um coletivo/laboratório social é desafiante, de fato, para o sujeito que tem o papel de intermediador, uma vez que posiçóes hierárquicas (cargos políticos ou técnicos) podem vir a gerar os fenômenos de impedimento apontados anteriormente (produção de silêncios e silenciamentos). Nesse sentido, a horizontalidade das discussões deve ser construída ao mesmo passo em que as relaçóes se tornem também cada vez menos "cristalizadas" e pautadas pela hierarquia de posiçóes sociais e políticas. Ardans (2009), a esse respeito, afirma que

\footnotetext{
"Fica claro que o propiciamento de atividades reflexivas seja para a população, seja para a equipe técnico-científica, pode possibilitar a crítica e a transformaçáo mútua da ciência e da sociedade, desde que se consiga gerar força e vontade política para reconhecer a sua relevância. Cabe refletir que o resultado desta pesquisa, de alta relevância para a psicologia social, mostra como é indispensável a interface com a política, especialmente com o exercício da cidadania e a construção da democracia. Trata-se do caráter político do trabalho psicossocial” (p. 167).
}

Tal trabalho psicossocial e comunitário, de caráter estritamente político, é, segundo Maritza Montero (2003), "um labor que constrói o espaço público, torna pública a opinião das pessoas, pede a sua satisfação e as capacita para obtê-la” (p. 163).

Um sistema que ilustra essa busca de expressão e articulação dentro de um coletivo é a Arquitetura da Capilaridade, sistema este que serviu como modelo para projetos de intervenção psicossocial, na gestão da Ministra Marina Silva (2003-2007) no Ministério do Meio 
Ambiente do Brasil. Durante este período, o Governo Federal fomentara programas e projetos voltados para o desenvolvimento de territórios sustentáveis no Brasil. Um dos projetos pensado a partir desta lógica era denominado de "Coletivos Educadores para Territórios Sustentáveis" os CETS (veja também Vichietti, (2011) Tassara et al. (no prelo) -, e tinha como proposta de metodologia a pesquisaação-participante. De acordo com Tassara e Tassara (2008), um coletivo educador pode ser descrito como segue.

\begin{abstract}
"Coletivo Educador é uma união de instituiçôes e/ou pessoas que trazem o apoio de suas instituiçóes para um processo de atuação educacional em um determinado território. Potencializando capacidades de pessoas e instituiçóes (universidades, secretarias de educação e de meio ambiente, ONGs, pastorais, organizaçóes populares, movimentos sociais, prefeituras, redes de educação ambiental, órgãos de assistência técnica e extensão rural, empresas, federaçôes, sindicais, entre outros), um Coletivo Educador se forma com o objetivo de atuar em processos de educaçấo ambiental, permanentes e articulados, voltados para atender à totalidade dos habitantes do território em que se inscreve. Ele pode ser constituído por educadores que, por exemplo, já desenvolvam açôes nos campos da educação ambiental, da educação popular, da formação d e professores, da extensão rural, da formação técnica socioambientalista. A principal função de um Coletivo Educador é atuar no planejamento pedagógico de programas educacionais para a formação de educadores ambientais e de seus multiplicadores, promovendo a articulação das instituiçóes e das políticas públicas, além da instrumentalização para a ação, a reflexão crítica e o aprofundamento conceitual, bem como a proatividade de seus participantes. Ou seja, CEs são grupos que trabalham em processos de mobilizaçáo social e de formaçáo de educadores ambientais populares, atuando também na criação e no fortalecimento de Comunidades de Aprendizagem e Qualidade de Vida (Com-Vidas). Coletivo Educador é também um programa da Diretoria de Educação Ambiental do Ministério do Meio Ambiente (MMA), iniciado em 2003". (p. 43-44)
\end{abstract}

A arquitetura da capilaridade (veja também Tassara e Tassara, 2008), por sua vez, pode ser descrita, de acordo com trabalho anterior (Tassara \& Ardans, 2006), da seguinte forma

\footnotetext{
A arquitetura da capilaridade, articulando setores planificadores com setores que serão sujeito (e não objeto) das planificaçôes, só será ético-democrática se pressupuser a transformação de qualquer membro do coletivo em um planificador e, portanto, em um co-governante que se auto-representa nos coletivos e que, no limite utópico, exauriria a distinção entre democracia representativa e democracia popular. Por outro lado, em um coletivo-educador, espera-se que seus membros participem, ou seja, que, além de presentes fisicamente, se expressem sobre os assuntos em pauta" (p. 65).
}

Ainda assim, é necessária muita atenção para o problema da representatividade, que pode afetar o funcionamento do grupo, se não observada e tratada corretamente. Estes autores afirmam que

\begin{abstract}
"alguns desses atores, ou dessas instâncias, são ou estão integradas por "representantes" de instituiçôes dos mais diversos tipos e presença na sociedade. Tal situação implica que quem representa, no coletivo, uma instituiçáo não poderá ter - porque submetido aos imperativos da instituiçáo que representa - o grau de autonomia e reflexividade que a pesquisa-ação, por definição, exige” (p. 64)
\end{abstract}

Dessa forma, retoma-se, mais uma vez, a característica desafiadora da condução de um coletivo que apresenta estas especificidades. A horizontalidade, a ética comunicativa, a postura democrática, são tanto meios quanto horizontes utópicos, em direção aos que o coletivo deve caminhar, sem nunca gozar de uma garantia total de chegada.

\section{Considerações finais}

Dessa forma, é possível concluir que a intervenção socioambiental, segundo a perspectiva aqui apresentada, tem por objetivo proporcionar o melhor cenário de convivência possível para o enfrentamento participativo na definição do projeto coletivo e do planejamento da açâo estratégica a ser aplicada em um determinado campo socioambiental que apresente um problema ou problemática. Onde o conjunto de pessoas que se sente envolvida em tal situaçáo (coletivo) tenha a oportunidade de definir a problemática e de discutir possibilidades de soluçôes que sejam buscadas e empreendidas de forma participativa, através de um processo que se pretende democrático e horizontal (pesquisa-ação, ética comunicativa).

Neste sentido, em consonância com trabalho anterior (Tassara \& Ardans, 2008), afirma-se que

\footnotetext{
"Esse processo crítico fomentaria a transparência das interaçóes humanas na vida social, aceitando o hibridismo gerado pela diversidade das possibilidades humanas, aproximando suas fronteiras de sua consecução utópica. Qual seria, então, o papel da psicologia social neste processo?
}

Quando as políticas públicas coincidem com a Política, no sentido aristotélico, a psicologia social é esse processo de desconstrução crítica e o conhecimento dele derivado sobre a vida social como um todo. Seu método, como já afirmado: a pesquisa-ação. Seu instrumento: a intervenção psicossocial emuladora da crítica do processo de socialização. Seus resultados: o incremento do processo de desnaturalização histórica e identitária e a emergência e/ou consolidação da consciência histórica e social dele resultante. $\mathrm{O}$ conhecimento daí decorrente é o esclarecimento do processo de construção histórica da interação humana e de seus resultantes psicossociais no plano material e simbólico (p. 328). 
O que se busca, assim, é aquilo que o grupo sinta como $o$ melhor (o Bem), o mais correto (o certo) e o mais bonito (o belo), para a sua convivência social. O horizonte utópico destes procedimentos pode ser descrito, de forma mais simples, como encontros humanos em um território em busca de uma construção compartilhada do futuro social.

Em conclusão, e transpondo as preconizaçóes de Lewin para o momento contemporâneo, Damergian (2009), ousase dizer que a intervenção socioambiental aqui proposta seria o esboço de um método de reconstrução cultural do presente na direçáo de um futuro utópico, em compromisso com a democracia e a emancipação, um caminho para uma verdadeira revolução pacífica.

\section{Referências}

Ab'saber, A. (2002) Entrevista concedida para o vídeodocumentário "USP Recicla". M. Tassara. Brasil: CECAE-USP.

Aragão, L. M. de C. (1997) Razão comunicativa e teoria social critica em Jürgen Habermas ( $2^{\text {a }}$ ed). Rio de Janeiro: Tempo Brasileiro.

Araujo, S. (2010) O Projeto de uma Psicologia Cientifica em Wilhelm Wundt. Uma nova interpretação. Juiz de Fora: Editora UFJF.

Ardans, O. (no prelo) Comunidad, enraizamiento, socioambiente: entre poética y politica. In Guevara, F. J. M.; Tassara E. T. de O. Problemáticas socio-ambientales en territorios latinoamericanos (no prelo). Puebla: UPAEPUniversidad Popular Autónoma del Estado de Puebla.

Ardans, O. (2013). Workshop "Reflexividade, self e política ambiental: a intervenção como construção compartilhada do futuro socioambiental planetário." Grupo de Política Ambiental do Instituto de Estudos Avançados (Coord. Eda Tassara). São Paulo: Instituto de Estudos Avançados - Universidade de São Paulo. Disponível em: http://iptv.usp.br/portal/home. jsp?tipo $=0 \& \_$_nstanceIdentifier $=08$ \&_EntityIdenti fier=uspoYKtt44drJCQ_MzYT9K9pHCPClqE01 uMGuPUXcYgqsE. \&idRepositorio $=0$ \& modelo $=0$

Ardans, O. (2009) Clínica psicossocial da identidade: subsidios para uma teoria da intervenção psicossocial em problemáticas socioambientais com base na análise das relaçóes do pensamento de J. Habermas com a teodicéia. Tese (Livre-Docência). Universidades de São Paulo.
Asch, S. E. (1952/1977) Psicologia Social. (Dante M. Leite e Miriam M. Leite trads., $4^{a}$ ed.) São Paulo: Editora Nacional.

Bakhtin, M. M. (1929/1981) Problemas da Poética de Dostoiévski. (Paulo Bezerra trad.) 1a . ed. Rio de Janeiro: Forense Universitária.

Bardi, L. B. (1983) Política Ambiental. Simpósio internacional. 35a Reunião Anual da Sociedade Brasileira para o Progresso da Ciência. Universidade Federal do Pará. Belém-PA.

Blumer, H. (1969/1998). 'The Methodological Position of Symbolic Interactionism'. In Symbolic Interactionism: Perspective and Method. Berkeley; University of California Press.

Bolzan, J. (2005). Habermas: Razão e racionalização. Ijuí: Unijuí.

Caorsi, C. E. (1994). Lógica, filosofía y psicoanálisis. Montevideo: Roca Viva.

Costa, L. R. F. (1986). Estratégias de planejamento. Ciência e Cultura, 38(8), 1366-1373.

Dallari, D. (2002). Direito de participação. In Sorrentino, M. (Coord.) Ambientalismo e participação na contemporaneidade (pp. 85-114). São Paulo: EDUC FAPESP.

Damergian, S. (2009). Para além da barbárie civilizatória o amor e a ética humanista. São Paulo: Casa do Psicólogo, 2009.

De Franco, A. e Pogrebinschi, Th. (Orgs.) (2008) Democracia cooperativa: escritos politicos de John Dewey: (19271939). Porto Alegre: EDIPUCRS.

Dewey, J. (1939/2008). “Democracia criativa: a tarefa diante de nós." In de Franco, Augusto e Pogrebinschi, Thamy (Orgs.) Democracia cooperativa: escritos politicos de John Dewey: (1927-1939) (pp. 135-152). Porto Alegre: EDIPUCRS.

Farr, R. M. (1996). As raizes da Psicologia Social Moderna (1872-1954). (Pedrinho Guareschi e Paulo V. Maya trads.) Petrópolis: Editora Vozes Ltda.

Feres Junior, J. e Pogrebinschi, Th. (2010). Teoria politica contemporânea. Uma introdução. Rio de Janeiro: Elsiever/Campus.

Fernandes, F. (1969/1975) Nota prévia. In Comunidade e sociedade no Brasil. Leituras básicas de introdução ao estudo macrossociológico do Brasil (2 ed). São Paulo: Ed. Nacional. 
Gentilini, J. A. (1999). Crise e planejamento educacional na América Latina: Tendências e perspectivas no contexto da descentralização. Tese de doutorado. Universidade Estadual de Campinas.

Goffman, E. (1959/2007). A representação do eu na vida cotidiana. (Maria Célia Santos Raposo trad.) 14 ${ }^{\mathrm{a}}$ ed. Petrópolis: Vozes.

Guba, E. (1990) The Paradigm dialog. New York: Sage.

Habermas, J. (1990/1993). Passado como futuro. (Flávio Siebeneichler trad.) Rio de Janeiro: Tempo Brasileiro.

Habermas, J. (1983/1989). Consciência moral e agir comunicativo. (Guido de Almeida trad.). Rio de Janeiro: Tempo Brasileiro.

Habermas, J. (1981/1987). Teoría de la acción comunicativa. Vol. I e II. (Manuel Jimenez Redondo trad.) Madrid: Taurus.

James, W. (1985). Pragmatismo e outros textos. 2a edição. (Jorge Caetano da Silva e Pablo Rubén Mariconda trads.) São Paulo: Abril Cultural.

Kohlberg, L. (1981/1992). Psicología del desarrollo moral. (Asun Z. Zárate trad.) Bilbao: Desclée de Brouwer.

Lalande, A. (1926/1996). Vocabulário técnico e crítico da filosofia. São Paulo: Martins Fontes.

Lewin, K. (1973). Princípios de psicologia topológica. (Alvaro Cabral trad.) São Paulo: Cultrix.

Lewin, K. (1951). Teoria de campo em ciência social. (Carolina M. Bori trad.) In Cartwright, D. (Org.) São Paulo: Pioneira.

Lewin, K. (1948/1983). Problemas de dinâmicas de grupo. São Paulo: Cultrix.

Marrow, A. J. (1969/1977). The practical theorist: The life and work of Kurt Lewin. New York: Teachers College Press.

Mead, G; H. (1934/2010). Mind, Self and Society: From the standpoint of a social behaviorist. Edited and with an introduction by Charles Morris. Chicago and London: The University of Chicago Press.

Melo, M. A. C. (1987). O planejamento para acelerar o processo. Rev. Serv. Pub., 114, 43-47.

Melo, M. A. C. (1979). Incrementalismo articulado: Estruturação do processo de planejamento. Rev. Econ. do Nord., 10[4: 927-946].

Melo, M. A. C. (1977). Articulated Incrementalism - a strategy for planning (with special reference to the design of na information system as na articulated task. Tese de doutorado: Whorton School, Pensylvania.

Montero, M. (2003). Teoría y práctica de la Psicología Comunitaria. Buenos Aires: Paidós.

Peirce, C. S. (1972). Semiótica e filosofia. São Paulo: Cultrix.

Piaget, J. (1980/1996). As formas elementares da Dialética. (Fernanda Mendes Luiz trad.) São Paulo: Casa do Psicólogo.

Piaget, J. (1970/1978). "A epistemologia genética”. In Piaget. Coleção Os pensadores. São Paulo: Abril Cultural.

Piaget, J. (1945/1965). "As operaçôes lógicas e a vida social" In J. Piaget. (1945) Estudos Sociológicos. (Reginaldo di Piero trad.). Rio de Janeiro: Companhia Editora Forense.

Pogrebinschi, Th. (2011). Judicialização ou representação? Política, direito e democracia no Brasil. Rio de Janeiro: Elsevier, Campus.

Pogrebinschi, Th. (2009). O enigma do politico. Marx contra a politica moderna. Rio de Janeiro: Ed. José Olympio.

Pogrebinschi, Th. (2005). Pragmatismo: Teoria social e politica. Rio de Janeiro: Relume Dumará.

Prudente, E. A. J. (1996). Direito à personalidade integral - cidadania Plena. Tese de Doutorado, Faculdade de Direito, Universidade de São Paulo, São Paulo. Acesso em 2013-07-14. Disponível em http://www.teses.usp. br/teses/disponiveis/2/2134/tde-30102007-105038/.

Santos, B. S. (1995). Pela mão de Alice: o social e o político na pós-modernidade. Porto: Afrontamento.

Santos, M. (1982/2004). Pensando o espaço do homem. $5^{\mathrm{a}}$ ed. São Paulo: EDUSP.

Tassara, E. T. de O. (1986). Uma estratégia participativa no planejamento educacional. Ciência e Cultura, 38(8), 1373-1380.

Tassara, E. T. de O. (1982). Análise de um programa de intervenção sobre o sistema educacional: da promessa a possibilidade. Tese de Doutorado. 2 vol. São Paulo: Universidade de São Paulo.

Tassara, E. T. de O. e Ardans, O. (2013). Participação emancipatória: reflexóes sobre a mudança social na complexidade contemporânea. In Sorrentino, M. et. ali. (2013) Educação Ambiental e políticas públicas: conceitos, fundamentos e vivências (p. 281294). Curitiba: Editora Appris Ltda.

Tassara, E. T. de O. e Ardans, O. (2012). Proposta de criação do Centro Articulador de Estudos e Investigaçôes em Politica Ambiental integrando atividades do Laboratório 
de Psicologia Socioambiental e Intervenção (LAPSIIPUSP), do Instituto Brasileiro de Educação, Ciência e Cultura (IBECC-UNESCO-SP) e do Grupo de Estudos em Psicologia Socioambiental (IEA-USP). Texto apresentado ao Instituto de Estudos Avançados da Universidade de São Paulo (IEA-USP).

Tassara, E. T. de O. e Ardans, O. (2008). A relação entre ideologia e crítica nas políticas: reflexóes a partir da psicologia social. Revista psicologia política, 7(14).

Tassara, E. T. de O. e Ardans, O. (2006). Educação Ambiental Crítica: pesquisa-ação, participação, silêncios e "silenciamentos". Revista Pesquisa em Educação. Ambiental, 1(1), 59-71.

Tassara, E. T. de O, Ardans, O., Massola, G. M., Arcaro, N. T. (no prelo). Un análisis de la política pública brasileña "colectivos educadores para territorios sostenibles". In Guevara, F. J. M.; Tassara E. T. de O. Problemáticas socio-ambientales en territorios latinoamericanos (no prelo). Puebla: UPAEPUniversidad Popular Autónoma del Estado de Puebla.

Tassara, E. T. de O. e Tassara, H. R. de O. (2008). Dicionário Socioambiental: Ideias, definiçôes e conceitos. São Paulo: FAARTE.

Vichietti, S. M. P. (2011). Coletivo educador da Região Norte da cidade de São Paulo. Relatório final apresentado ao Fundo Nacional do Meio Ambiente do Ministério do Meio Ambiente. São Paulo, IBECC/ UNESCO, São Paulo. 
